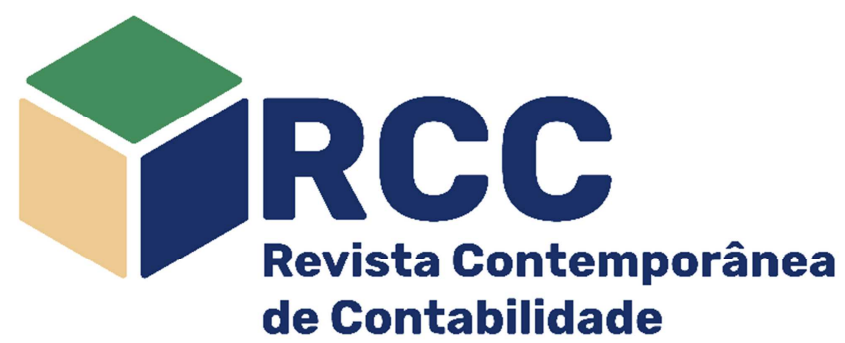

\title{
Performance do modelo de cinco fatores de Fama e French na precificação de anomalias no mercado brasileiro
}

\author{
Performance of the Fama-French five-factor model in the pricing of anomalies in the Brazilian market
}

\section{Desempeño del modelo de cinco factores de Fama y French en la valoración de anomalías en el mercado brasileño}

\author{
Claudia Faria Macie \\ Mestra em Administração (CEFET-MG), Belo \\ Horizonte/MG, Brasil \\ cfariam@gmail.com \\ https://orcid.org/0000-0002-5812-575X (])
}

Hudson Fernandes Amaral

Doutor em Administração na Université Pierre Mendés

France Grenoble II. Professor do Programa de Mestrado em Administração (CEFET-MG). Professor do Programa de

Mestrado em Administração (UNIHORIZONTES), Belo

Horizonte/MG, Brasil

hfamaral.cepead@gmail.com https://orcid.org/0000-0001-8455-0285 (1)

Laíse Ferraz Correia* Doutora em Administração (UFMG) Professora do Programa de Pós-Graduação em Administração (CEFET-MG), Belo Horizonte/MG, Brasil laise@cefetmg.br https://orcid.org/0000-0002-0977-9298

\author{
Joyce Mariella Medeiros Cavalcanti \\ Doutora em Administração (UFMG) \\ Professora do Programa de Pós-Graduação em \\ Administração da Universidade Potiguar, Natal/RN, Brasil \\ joyce.cavalcanti@unp.br \\ https://orcid.org/0000-0001-6213-1266 (1)
}

Endereço do contato principal para correspondência* Avenida Amazonas, № 7675, Bairro: Nova Gameleira, CEP: 30510-000 - Belo Horizonte/MG, Brasil

\section{Resumo}

O objetivo deste artigo foi analisar a performance do modelo de cinco fatores de Fama e French no mercado acionário brasileiro, em comparação às dos modelos de três e quatro fatores, bem como verificar se existem prêmios de risco associados às anomalias tamanho, índice book-to-market, momento, lucratividade e investimento. Buscou-se, assim, analisar a eficiência desses modelos como ferramentas de apoio à tomada de decisão financeira em condições de risco. Para isso, utilizou-se a metodologia de Fama e MacBeth. Os resultados das regressões do primeiro passo sugeriram que o modelo de cinco fatores apresenta o melhor desempenho na explicação dos retornos das ações quando comparado aos demais. No entanto, nas regressões do segundo passo, não se verificaram prêmios de risco associados à lucratividade e ao investimento, fatores adicionados ao modelo três fatores. Apenas os riscos relacionados ao mercado, tamanho e índice book-to-market explicaram consistentemente os retornos cross-section das ações.

Palavras-chave: Precificação de ativos; Anomalias de mercado; Modelos de três e cinco fatores de Fama e French; Modelo de quatro fatores de Carhart

\begin{abstract}
The purpose of this paper was to analyze the performance of the Fama-French five-factor model in the Brazilian stock market, in comparison to the three-and four-factor models, as well as to verify whether there are risk premiums associated to the anomalies size, book-to-market index, momentum, profitability and investment. Thus, we sought to analyze the efficiency of these models as a tool to support financial decision making in risk conditions. For this, the Fama-MacBeth methodology was used. The results of the first step regressions suggested that the Fama-French five-factor model presents the best performance in explaining the stock returns when compared to the others. However, in the results of the second step regressions, there were not found risk premiums associated to the profitability and investment factors, added to the three-factor model. Only the risks related to market, size, and book-to-market index consistently explained the crosssection of stock returns.
\end{abstract}

Keywords: Asset pricing; Market anomalies; Fama-French three-and five-factor models; Carhart four factor model 


\section{Resumen}

El objetivo de este artículo fue analizar el desempeño del modelo de cinco factores de Fama y French en el mercado brasileño, en comparación con los modelos de tres y cuatro factores, así como verificar si existen primas de riesgo por las anomalías tamaño, ratio book-to-market, momentum, rentabilidad y inversión. Así, buscamos analizar su eficiencia como herramienta de apoyo a la toma de decisiones en condiciones de riesgo. Para eso se utilizó la metodología de Fama y MacBeth. Los resultados del primer paso sugirieron que el modelo de cinco factores presenta el mejor desempeño para explicar la rentabilidad de las acciones en comparación con los demás. Sin embargo, en los resultados del segundo paso, no se encontraron primas de riesgo asociadas a la rentabilidad e inversión, adicionados al modelo de tres factores. Solo los riesgos relacionados con el mercado, tamaño y ratio book-to-market explicaron consistentemente los rendimientos de las acciones.

Palabras clave: Valoración de activos; Anomalías de mercado; Modelos de tres y cinco factores de Fama y French; Modelo de cuatro factores de Carhart

\section{Introdução}

Nos mercados de capitais são negociados diversos títulos das companhias neles listadas, os quais carregam em seus preços informações sobre características dessas companhias e/ou do ambiente macroeconômico, as quais implicam, por sua vez, níveis diversos de exposição a fontes de risco sistêmico. Tais fatores levam os investidores a exigir um prêmio ao adquirir esses ativos, isto é, a precificar os riscos.

No mercado brasileiro, especificamente, observou-se um crescimento do volume de emissões de títulos nos últimos cinco anos, considerando-se as diferentes modalidades negociadas (renda fixa e variável). De 2015 a 2019, a captação nesse segmento do mercado financeiro passou de $R \$ 122$ a $R \$ 435$ bilhões de reais - em valores aproximados. Em 2020, registrou-se, entretanto, uma queda nesse ritmo de crescimento, em que foram captados cerca de $\$ 300$ bilhões de reais, haja vista o contexto de retração econômica (Anbima, 2020). Informações dessa natureza são importantes na medida em que revelam a pertinência de se desenvolver modelos de precificação de ativos que efetivamente auxiliem os investidores na tomada da decisão de alocação de seus recursos nas melhores opções de portfólios de títulos negociados nos mercados de capitais (Paliienko, Naumenkova \& Mishchenko, 2020).

A literatura financeira tem sido profícua na proposição de modelos que buscam explicar como os ativos são precificados em função de seus níveis de risco sistêmico. A partir do Capital Asset Pricing Model (CAPM) de Sharpe (1964), Lintner (1965) e Mossin (1966) - elaborado no arcabouço da teoria de médiavariância de Markowitz (1952) -, do Intertemporal Capital Asset Pricing Model (ICAPM) de Merton (1973) e da Arbitrage Pricing Theory (APT) de Ross (1976) - desenvolvidos no contexto de modelos multifatoriais que relacionam o retorno a diferentes fontes de risco sistêmico -, vários modelos empíricos vêm sendo propostos e testados ao longo dos anos, os quais, em geral, incorporam o efeito de aspectos macroeconômicos ou de características das firmas. Como sugerem Paliienko et al. (2020), a adequação de um modelo para os processos de precificação de ativos reside na sua capacidade de explicar as anomalias identificadas nos estudos empíricos, tendo em vista que elas decorrem ou de uma falha de mercado ou da especificação incorreta de modelos anteriores, em particular, do CAPM. Para Fama e French (2018), esse cenário incita o debate sobre quais fatores podem ser incluídos nos modelos.

Baseando-se no enfoque da APT e do ICAPM - e nas evidências empíricas relativas às anomalias do CAPM documentadas ao longo da década de 80 -, Fama e French (1993) propuseram o modelo de três fatores, em que os retornos dos ativos são explicados não apenas pelo prêmio de mercado, mas também pelos fatores tamanho e índice book-to-market - anomalias documentadas por Banz (1981) e Lakonishok e Shapiro (1986), respectivamente. Com a identificação do efeito momento por Jegadeesh e Titman (1993), Carhart (1997) propôs a incorporação de um fator representativo dessa anomalia ao modelo de três fatores de Fama e French, o que resultou no modelo de quatro fatores. Nos anos que se seguiram, diversas anomalias foram sendo identificadas. Como consequência, a precificação delas foi testada - por exemplo, em Fama e French (1996, 2008).

A partir das evidências dos efeitos de lucratividade e investimento das empresas (crescimento do ativo) sobre o retorno de portfólios de ações - documentadas em estudos, tais como, Titman, Wei e Xie (2004) e Novy-Marx (2013) -, Fama e French (2015) adicionaram dois fatores ao seu modelo anterior para capturar essas anomalias, propondo, dessa forma, o modelo de cinco fatores. Os resultados dos testes para o mercado norte-americano apontaram que o modelo de cinco fatores tem maior poder de explicação dos retornos do que os modelos de três e quatro fatores.

A relevância das anomalias investimento e lucratividade instigou estudos empíricos do modelo de cinco fatores em diferentes mercados. No brasileiro, pode-se citar, entre outros, Siqueira, Amaral e Correia (2017), Vieira, Maia, Klotzle e Figueiredo (2017) e Leite, Klotzle, Pinto e Silva (2018). Alguns desses testes mostram que, no nosso mercado, assim como no norte-americano, esse modelo tem um desempenho superior na explicação dos retornos de ações, visto que o coeficiente de determinação se mostrou mais elevado com a adição dos fatores de risco construídos a partir dessas duas variáveis contábeis. 
De um lado, constata-se que os diversos estudos empíricos dos modelos de fatores no mercado brasileiro (e em outras economias emergentes) tiveram o propósito comum de testar a aplicabilidade dos modelos em contexto diferente daqueles para os quais foram desenvolvidos. Isso pode ser explicado, como argumentam Fama e French (1998) e Atilgan, Demirtas e Gunaydin (2020), pelo (i) potencial dos mercados emergentes de propiciar um teste out-of-sample desses modelos, uma vez que as especificidades desses mercados os tornam segmentados em relação aos mercados desenvolvidos; ou, ainda, pelas (ii) evidências de que, como sugerem Gregory, Tharyan e Christidis (2013), a partir dos argumentos e resultados de Griffin (2002), os modelos do tipo Fama e French têm melhor performance quando são realizados para países, se comparados aos modelos mundiais (ou suas versões internacionais). Evidências como as de Matos e Rocha (2009), Santos, Famá e Mussa (2012) e Leite et al. (2018) revelaram a eficiência dos modelos (mais especificamente do de quatro fatores). De outro lado, os estudos sobre o poder preditivo dos modelos no mercado brasileiro apresentam divergências de resultados. As evidências empíricas de Mussa, Rogers e Securato (2009) e Rizzi (2012), por exemplo, sugerem que nenhum dos modelos de fatores por eles testados foi suficiente para explicar as variações dos retornos. As evidências empíricas não indicam, portanto, um modelo que seja consistentemente robusto para o nosso mercado. Esse dissenso mostra que ainda há espaço para a discussão sobre o processo gerador de retornos de ações no mercado brasileiro. Como sugere Griffin (2002), utilizar um modelo incorreto pode levar a erros nos processos de tomada de decisão, tais como, de orçamento de capital, avaliação de portfólios e análise de risco.

Nesse contexto, surgiu a motivação desta pesquisa que consistiu em testar a hipótese de superioridade do modelo de cinco fatores de Fama e French (2015) em explicar os retornos de ações negociadas no mercado brasileiro (primeira hipótese). Buscou-se, assim, comparar a performance dos modelos de (i) três fatores de Fama e French (1993), (ii) quatro fatores de Carhart (1997) e (iii) cinco fatores de Fama e French (2015). Em seguida, buscou-se testar a hipótese de existência de prêmios de risco (precificação) associados aos fatores desses modelos construídos com base nas anomalias tamanho, índice book-to-market, momento, lucratividade e investimento (segunda hipótese).

Como diferencial em relação a outros estudos realizados no Brasil, neste artigo, utilizou-se a metodologia de Fama e MacBeth (1973) para estimação dos modelos, que compreende a realização de regressões em dois passos. Sequencialmente, essas etapas permitiram (i) avaliar a performance do modelo de cinco fatores (em relação às dos outros modelos) e (ii) verificar se existem prêmios de risco associados aos fatores dos modelos testados. O modelo de cinco fatores foi menos investigado no mercado brasileiro, se comparado aos modelos de três e quatro fatores, sendo, portanto, pertinente utilizá-lo como teste out-ofsample. Ademais, são ainda escassas as pesquisas que buscam também avaliar a precificação dos fatores de risco dos modelos de três, quatro e cinco fatores, isto é, que buscam verificar se os riscos ajudam a explicar os retornos cross-section de portfólios de ações construídos com base em anomalias. A maioria concentra-se tão-somente na análise do desempenho dos modelos (regressões do primeiro passo). Este estudo mostra-se, assim, pertinente no campo da tomada de decisão de investimentos no Brasil, haja vista seu propósito de analisar modelos de precificação de ativos que capturam as anomalias mais comumente documentadas.

\section{Revisão da Literatura}

\subsection{Modelos de Precificação de Fama e French e de Carhart}

A partir de evidências empíricas de que os retornos das ações estariam associados às anomalias tamanho e índice book-to-market, além do prêmio de mercado (CAPM), Fama e French (1993) propuseram o modelo de três fatores, expresso pela equação econométrica (1). O fator SMB (tamanho) resulta da diferença entre os retornos de portfólios de ações de pequenas empresas (small) e os de ações de grandes empresas (big). O fator HML (índice book-to-market) resulta da diferença entre os retornos de portfólios de ações de empresas de alto índice book-to-market (high) e os de baixo índice book-to-market (low). O fator de mercado $\left(R_{m}-R_{f}\right)$ é diferença entre o retorno do portfólio de mercado e o do ativo livre de risco. Para testar esse modelo, Fama e French (1993) utilizaram os dados de Fama e French (1992), mas com abordagem distinta: modelo de séries temporais de Black, Jensen e Scholes (1972).

$$
R_{i}-R_{f}=\alpha_{i}+\beta_{i}\left(R_{m}-R_{f}\right)+s_{i} S M B+h_{i} H M L+\varepsilon_{i}
$$

Adiante, com a evidência de Jegadeesh e Titman (1993) de que a estratégia de comprar ações com altos retornos passados e vender ações com baixos retornos passados (momento) produzia retornos anormais positivos durante o ano subsequente, os estudos sobre precificação, entre eles Fama e French (1996), passaram a testar também essa anomalia. Fama e French (1996) observam que, apesar de o modelo de três fatores explicar muitas das anomalias identificadas nos estudos empíricos, ele não captura o efeito momento. Carhart (1997) adicionou um fator representativo dessa anomalia ao modelo de três fatores para avaliar a performance de fundos mútuos. O modelo de quatro fatores (equação econométrica 2) incorpora WML (momento), que resulta da diferença entre os retornos de portfólios vencedores (winners - 
ações com os maiores retornos acumulados no passado recente) e perdedores (losers - ações com os menores retornos acumulados no passado recente).

$$
R_{i}-R_{f}=\alpha_{i}+\beta_{i}\left(R_{m}-R_{f}\right)+s_{i} S M B+h_{i} H M L+\mathrm{w}_{i} \mathrm{WML}+\varepsilon_{i}
$$

Fama e French (2015), motivados pelas evidências anteriores de que as anomalias lucratividade e investimento também contribuem para a descrição dos retornos de ações (Titman et al., 2004; Novy-Marx, 2013; Fama \& French, 2008; Fama \& French, 2012), adicionaram dois fatores ao modelo Fama-French (1993) para capturar essas fontes de risco sistêmico, propondo, assim, o modelo de cinco fatores (equação econométrico 3). O fator RMW (lucratividade) resulta da diferença entre o retorno do portfólio de ações com desempenho operacional elevado (robusto) e o com desempenho operacional baixo (fraco). O fator CMA (investimento) resulta da diferença dos retornos médios dos portfólios de empresas que realizaram investimentos baixos (conservadores) e empresas que realizaram investimentos elevados (agressivos).

$$
R_{i}-R_{f}=\alpha_{i}+\beta_{i}\left(R_{m}-R_{f}\right)+s_{i} S M B+h_{i} H M L+r_{i} R M W+c_{i} C M A+\varepsilon_{i}
$$

Nos testes empíricos desse modelo, cuja amostra englobou 606 observações de ações da NYSE, AMEX e NASDAQ no período 1963-2013, Fama e French (2015) formaram, inicialmente, 25 portfólios com base nas combinações das anomalias: i) tamanho e índice book-to-market; ii) tamanho e lucratividade; iii) tamanho e investimento. Em seguida, formaram 32 portfólios a partir das combinações de: i) tamanho, índice book-to-market e lucratividade; ii) tamanho, índice book-to-market e investimento; iii) tamanho, lucratividade e investimento. Os resultados sugeriram um padrão de retorno médio relacionado ao tamanho, índice book-to-market, lucratividade e investimento. Apesar de o teste de Gibbons, Ross e Shanken (1989) - GRS - rejeitar o modelo de cinco fatores (os interceptos se mostraram, conjuntamente, diferentes de zero), ele apresentou um poder explicativo dos retornos entre $71 \%$ e $94 \%$.

Além disso, Fama e French (2015) encontraram que o poder explicativo do fator HML é capturado, em grande parte, por RMW e CMA. Para solucionar a redundância, esse fator foi ortogonalizado: obtido por meio da regressão entre HML e os demais fatores. Em conclusão, Fama e French (2015) sugerem que o principal problema do modelo é a incapacidade de capturar totalmente os baixos retornos de ações muito pequenas (microcaps).

O modelo de cinco fatores foi, posteriormente, testado em mercados internacionais: América do Norte, Europa, Japão e Ásia-Pacífico. Fama e French (2017) observaram que os retornos das ações para as regiões da América do Norte, Ásia-Pacífico e Europa aumentam com o índice book-to-market e a lucratividade, e diminuem com o investimento. Para o Japão, os retornos médios possuem fraca relação com a lucratividade ou com o investimento, ao passo que possuem forte relação com o índice book-tomarket. Os resultados também revelaram que o principal problema do modelo está associado às ações muito pequenas (microcaps), cujos retornos se comportam como os de empresas que investem agressivamente, ainda que possuam baixa lucratividade - similarmente ao documentado em Fama e French (2015; 2016).

\subsection{Evidências Empíricas de Anomalias no Mercado Brasileiro}

Os modelos de precificação de Fama e French (1993; 2015) e Carhart (1997) vêm sendo utilizados por grande parte dos estudos sobre precificação de ativos no mercado brasileiro. Nessas análises, 0 desempenho dos modelos fatorais é, geralmente, confrontado com o do CAPM. Nessa perspectiva, Rodrigues (2000) e Málaga e Securato (2004) avaliaram o impacto dos fatores mercado, tamanho e índice book-to-market sobre os retornos de ações listadas na Bolsa de Valores de São Paulo. O desempenho do modelo de três fatores se mostrou superior ao do CAPM em ambos os estudos.

O desempenho do modelo de Carhart (1997), comparado tanto ao do CAPM quanto ao do modelo de três fatores, também foi testado por diversos estudos brasileiros. Por um lado, há evidências de performance superior desse modelo em relação às dos modelos de três fatores e CAPM. Matos e Rocha (2009) observaram que: (i) o CAPM foi incapaz de capturar as fontes comuns de risco para a amostra de 18 fundos de investimento no período 1997-2006; (ii) o poder preditivo do modelo de quatro fatores é superior aos dos modelos CAPM e de três fatores. Similarmente, Santos et al. (2012) observaram, para uma amostra de ações negociadas na Bolsa de Valores de São Paulo no período 1995-2006, que: i) o modelo de três fatores apresentou performance superior à do CAPM; ii) o modelo de quatro fatores foi superior ao de três na explicação das variações dos retornos dos portfólios. Por outro lado, não há evidências consistentes de prêmios de risco associados aos fatores do modelo de Carhart (1997). Embora Mussa et al. (2009) e Rizzi (2012) - que aplicaram a metodologia de Fama e MacBeth (1973) - tenham encontrado resultados similares quanto à performance superior do modelo de quatro fatores, nenhum entre os modelos por eles testados foi suficiente para explicar as variações dos retornos cross-section, haja vista as significâncias estatísticas dos interceptos das regressões. Além disso, Mussa et al. (2009) encontraram prêmios de risco associados apenas aos fatores mercado e índice book-to-market, que se mostraram consistentemente significativos. 
Não foram observados prêmios de risco associados ao tamanho e momento. Rizzi (2012), por sua vez, documentou apenas o prêmio de mercado.

Com a proposição do modelo de Fama e French (2015), a sua aplicabilidade ao mercado brasileiro também passou a ser testada. Martins e Eid Jr. (2015) mostraram que os fatores mercado, tamanho e índice book-to-market parecem capturar a maior parte da variação nos retornos dos portfólios de ações negociadas na Bolsa de Valores de São Paulo entre 2000 e 2015. O modelo de cinco fatores explicou quase a totalidade da variação dos retornos, sendo o seu desempenho superior ao do modelo Fama-French (1993). Porém, os fatores de lucratividade e investimento apresentaram menor impacto sobre os retornos, se comparados aos dos fatores do modelo de Fama e French (1993).

Posteriormente, Siqueira et al. (2017) empregaram os modelos de três, quatro e cinco fatores para verificar se a assimetria informacional - mensurada pela Volume-Synchronized Probability of informed trading - representa um fator explicativo das variações dos retornos de portfólios de ações negociadas na Brasil, Bolsa, Balcão - B3. Os seus resultados indicaram que os fatores mercado, tamanho, lucratividade, investimento e informação assimétrica formam a combinação que melhor explica os retornos dos portfólios. Assim como em Fama e French (2015), o HML se mostrou redundante.

A performance dos modelos de três, quatro e cinco fatores e do CAPM em mercados emergentes Brasil, Chile, México, Argentina, Índia, China, Tailândia, Malásia, Turquia, Polônia, Romênia e Rússia, foi analisada por Leite et al. (2018). Esses autores observaram que os modelos de quatro e cinco fatores têm um desempenho melhor do que o de três fatores na maioria dos testes no período 2007-2017. Porém, assim como em Fama e French (2015), o HML se tornou um pouco redundante na presença dos fatores lucratividade e investimento. Isto é, nos testes para avaliar se as influências desse fator são capturadas pelos demais fatores do modelo, o seu efeito foi praticamente todo explicado por lucratividade e investimento.

Com um foco diferente, Vieira et al. (2017) testaram a capacidade de precificação dos fatores de risco do modelo de cinco fatores de Fama e French (2015) para carteiras setoriais. Os seus resultados sugeriram maior relevância do fator investimento, estatisticamente significativo em três dos cinco setores analisados.

Diante do exposto, percebe-se um dissenso nos estudos não apenas quanto ao desempenho dos modelos de precificação de ativos testados no mercado brasileiro, mas também quanto aos prêmios de risco relevantes, lacuna essa explorada neste artigo.

\section{Metodologia}

\subsection{Amostra Analisada}

A população objeto de análise abrangeu todas as ações listadas na B3 entre junho de 2000 e junho de 2017. Em nível individual, foram coletados dados de junho de 1999 a julho de 2018, necessários à construção dos fatores dos modelos de Fama e French (1993; 2015) e de Carhart (1997). Os critérios utilizados para a seleção da amostra foram a disponibilidade de: (i) valor de mercado em 30 de junho, com tolerância dos 30 dias prévios; (ii) valor de mercado e valor do Patrimônio Líquido positivo na data de 31 de dezembro do ano anterior - com tolerância de 30 dias anteriores para a capitalização de mercado; (iii) ativo total em 31 de dezembro dos dois anos prévios à formação dos portfólios; (iv) lucro operacional em 31 de dezembro do ano anterior ao de formação do portfólio; e (v) cotações mensais consecutivas das ações nos 12 meses anteriores e posteriores à data de formação dos portfólios (as cotações do período anterior foram necessárias à construção do fator momento; e as do posterior, ao cálculo do retorno das ações). As ações de empresas financeiras foram excluídas da amostra devido ao seu alto grau de endividamento - assim como em Fama e French (1992; 1993). As informações foram tratadas ao nível de ativo devido ao número pequeno de ações listadas na B3. Ou seja, as empresas que possuíam ações preferenciais e ordinárias foram tratadas como dois ativos diferentes. Isso implica que duas ações da mesma empresa podem ter sido utilizadas para compor diferentes fatores de risco.

Como resultado, foram coletados os dados para 388 ações em todo o período amostral. Cada portfólio compôs-se de, no mínimo, três ações - procedimento similar ao de Málaga e Securato (2004) e Mussa et al. (2009). Para o tratamento dos dados, utilizou-se o Python.

Os preços de fechamento das ações foram ajustados aos seus proventos, os retornos dos ativos individuais foram transformados em logaritmo neperiano e o retorno dos portfólios foi obtido mediante a equação 4.

$$
R_{p, t}=\sum_{i=1}^{n} \frac{V M_{i, t}}{V M_{p, t}}\left(R_{i, t}\right)
$$

Em que: $R_{p, t}$ é o retorno do portfólio $p$ em $t ; V M_{i, t}$ é o valor de mercado da ação $i$ em $t ; V M_{p, t}$ é o valor de mercado do portfólio $p$ em $t$; e $R_{i, t}$ é a taxa de retorno do ativo em $t$. 
A forma de operacionalizar as variáveis referentes às características subjacentes à formação dos portfólios está apresentada na Tabela 1.

Tabela 1

Operacionalização das variáveis (características) subjacentes aos portfólios

Variáveis

Tamanho (Valor

de Mercado)
Fórmula

$$
V M_{i, t}=P_{i, t} \times N_{i, t}
$$

Descrição

$V M_{i, t}$ é o valor de mercado da ação $i$ no tempo $t$;

$P_{i, t}$ é o preço da ação $i$ no tempo $t$;

$N_{i, t}$ é o número de ações $i$ em circulação no tempo $t$.

$B / M_{i, t}$ é o índice book-to-market da empresa $i$, no tempo $t$; $P L_{i, d e z(t-1)}$ é o valor do patrimônio líquido da empresa $i$ em 31 de dezembro do ano $t-1$, em relação ao ano de formação do portfólio;

Índice Book-to- $\quad B / M_{i, t}=\frac{P L_{i, \operatorname{dez}(t-1)}}{V M_{i, \operatorname{dez}(t-1)}}$
Market $V M_{i, d e z(t-1)}$ é o valor de mercado da empresa $i$ em 31 de dezembro do ano $t-1$, em relação ao ano de formação do portfólio.

Lucr $_{i, t}$ é a lucratividade da empresa $i$, no tempo $t$

$L o p_{i, d e z(t-1)}$ é o valor do lucro operacional da empresa $i$ em 31 de dezembro do ano $t-1$;

Lucratividade $\quad \operatorname{Lucr}_{i, t}=\frac{\operatorname{Lop}_{i, \operatorname{dez}(t-1)}}{P L_{i, \operatorname{dez}(t-1)}}$

$P L_{i, d e z(t-1)}$ é o valor do patrimônio líquido da empresa $i$ em 31 de dezembro do ano $t-1$.

Invi,t é o valor do investimento da empresa $i$, no tempo $t$; $A T_{i, d e z(t-1)}$ é o valor do ativo total da empresa $i$ em 31 de dezembro do ano $t-1$;

$A T_{i, d e z(t-2)}$ é o valor do ativo total da empresa $i$ em 31 de dezembro do ano $t-2$, sendo $t o$ ano de formação do portfólio.

Fonte: Adaptado de Fama e French (1993, 2015) e Carhart (1997).

\subsection{Variáveis Independentes - fatores right-hand-side (RHS)}

Para a criação dos fatores de risco utilizados nesta pesquisa (variáveis independentes das regressões do primeiro passo), fez-se uso dos procedimentos descritos em Fama e French $(1993,2015)$ e Carhart (1997) dispondo-se, no total, de 388 ações negociadas na B3. Os fatores dos modelos de três e quatro fatores foram construídos utilizando critérios similares, consistindo na classificação das ações conforme o tamanho, índice book-to-market e, para o fator momento, desempenho no ano anterior (onze meses anteriores). Para o modelo de cinco fatores, as ações foram classificadas de acordo com seu tamanho, índice book-to-market, lucratividade e investimento. Para a formação dos portfólios, em junho de cada ano $t$, começando em 2000 e terminando em 2017, os ativos foram classificados de forma crescente pelo seu valor de mercado. Uma vez estimado o valor de mercado para cada ativo, eles foram divididos pela sua mediana nos grupos (i) big (B) e (ii) small (S), sendo o primeiro grupo composto pelos ativos com alto valor de mercado (com capitalização de mercado acima da mediana); e o segundo por aqueles com baixo valor de mercado (com capitalização de mercado abaixo da mediana).

Após a classificação anterior, também no mesmo mês $t$, os ativos foram reordenados com base em seus valores de índice book-to-market, momento, investimento e lucratividade, formando os grupos baixo (low), médio (medium) e alto (high). Ou seja, os fatores foram obtidos mantendo-se o tamanho como a variável principal; e alterando-se a segunda variável (classificatória) de modo a formar os portfólios com a combinação de duas características das firmas, seguindo-se um critério $2 \times 3$.

Para o índice book-to-market, as ações foram ordenadas e separadas em três grupos de acordo com seus percentis, de modo que, sequencialmente, estivessem contidas neles: (i) $30 \%$ das ações com os valores mais baixos de índice book-to-market (low); (ii) 40\% das ações com valores medianos de índice book-to-market (medium); e (iii) $30 \%$ das ações com os valores mais altos de índice book-to-market (high).

Para o indicador momento, foi realizado um procedimento similar, em que as ações foram reordenadas de forma crescente, segundo seu retorno acumulado nos últimos 11 meses. As ações foram separadas em três grupos, de modo que contivessem: (i) 30\% das ações com os menores retornos; (i) $40 \%$ das ações com retornos medianos; e, por fim, (iii) 30\% das ações com os maiores retornos. Desconsiderouse o retorno do último mês, conforme Jegadeesh e Titman (1993) e Carhart (1997).

Para a lucratividade, as ações foram ordenadas e divididas em três grupos, também segundo os percentis 30-40-30. No primeiro grupo estão as ações com as lucratividades mais baixas - fracas (weak). No segundo, as ações com as lucratividades medianas (medium). No último, as ações com as lucratividades mais elevadas - robustas (robust). 
Para o investimento, os ativos foram ordenados em função ascendente e separados em três grupos, seguindo o mesmo procedimento descrito anteriormente. No primeiro grupo constam as ações com os investimentos mais baixos - conservadores (conservative); no segundo, as ações com investimentos medianos; e, por fim, no último, as ações com os investimentos mais altos - agressivos (aggressive).

O procedimento de formação dos portfólios foi repetido em junho de cada ano do período amostral para que, assim, as novas informações publicadas e disponíveis estivessem incorporadas na composição dos portfólios. Dessa forma, para cada ano do período amostral, de julho do ano $t$ até junho do ano $t+1$, foram calculados os retornos mensais de cada portfólio, sendo considerada a ponderação pelo valor de mercado de cada ativo, em relação ao valor de mercado total do portfólio.

Após esses procedimentos, obtiveram-se 30 portfólios RHS (Apêndice 1), os quais foram utilizados na construção dos fatores de risco (variáveis independentes) dos modelos de precificação estimados no primeiro passo da metodologia de Fama e MacBeth (1973). A operacionalização dos fatores RHS dos modelos de três, quatro e cinco fatores - está apresentada na tabela 2.

Tabela 2

Operacionalização dos fatores RHS dos modelos de três, quatro e cinco fatores

\begin{tabular}{|c|c|c|}
\hline Fatores RHS & Fórmulas & Modelos \\
\hline \multirow[b]{2}{*}{$\begin{array}{l}\text { Fator SMB. Diferença entre os retornos } \\
\text { médios dos portfólios small e big. }\end{array}$} & $\begin{array}{c}S M B=\bar{R}_{S}-\bar{R}_{B} \\
\bar{R}_{S}=\frac{S L_{t}+S M_{t}+S H_{t}}{3} ; \bar{R}_{B}=\frac{B L_{t}+B M_{t}+B H_{t}}{3}\end{array}$ & $\begin{array}{l}3 \text { fatores } \\
4 \text { fatores }\end{array}$ \\
\hline & $\begin{array}{c}S M B=\bar{R}_{S}-\bar{R}_{B} \\
\bar{R}_{S}=\frac{S L_{t}+S N_{B M t}+S H_{t}+S W_{t}+S N_{L U C t}+S R_{t}+S C_{t}+S N_{I N V t}+S A_{t}}{9} \\
\bar{R}_{B}=\frac{B L_{t}+B N_{B M t}+B H_{t}+B W_{t}+B N_{L U C t}+B R_{t}+B C_{t}+B N_{I N V t}+B A_{t}}{9}\end{array}$ & 5 fatores \\
\hline $\begin{array}{l}\text { Fator HML. Diferença entre os retornos } \\
\text { médios dos portfólios high e low book- } \\
\text { to-market. }\end{array}$ & $\begin{array}{l}H M L_{t}=\bar{R}_{H}-\bar{R}_{L} \\
\bar{R}_{H}=\frac{S H_{t}+B H_{t}}{2} ; \bar{R}_{L}=\frac{S L_{t}+B L_{t}}{2}\end{array}$ & $\begin{array}{l}3,4 \text { e } 5 \\
\text { fatores }\end{array}$ \\
\hline $\begin{array}{l}\text { Fator MKT - Prêmio de Mercado. } \\
\text { Diferença entre os retornos mensais } \\
\text { médios, ponderados pelo valor de } \\
\text { mercado mensal, de todas as ações da } \\
\text { amostra analisada em cada ano do } \\
\text { período amostral e o retorno mensal do } \\
\text { Certificado de Depósito Interbancário - } \\
\text { CDI. }\end{array}$ & $\begin{array}{c}M K T=R_{\text {carteira de mercado,t }}-R_{C D I, t} \\
\mathrm{R}_{\text {carteira de mercado }, \mathrm{t}}=\text { proxy para a carteira de mercado. } \\
\mathrm{R}_{\mathrm{CDI}, \mathrm{t}}=\text { proxy para o retorno do ativo livre de risco } \\
\text { (CDI). }\end{array}$ & $\begin{array}{l}3,4 \text { e } 5 \\
\text { fatores }\end{array}$ \\
\hline $\begin{array}{l}\text { Fator WML - momento. Diferença entre } \\
\text { os retornos médios dos portfólios de } \\
\text { ações vencedoras (winners) e os } \\
\text { retornos médios dos portfólios de } \\
\text { ações perdedoras (losers). As ações } \\
\text { vencedoras são aquelas com os } \\
\text { maiores retornos acumulados nos } \\
\text { últimos onze meses; e as perdedoras, } \\
\text { os menores retornos. }\end{array}$ & $\begin{array}{l}W M L_{t}=\bar{R}_{W}-\bar{R}_{L} \\
\bar{R}_{W}=\frac{S W_{t}+B W_{t}}{2} ; \bar{R}_{L}=\frac{S L+B L_{t}}{2}\end{array}$ & 4 fatores \\
\hline $\begin{array}{l}\text { Fator RMW - lucratividade. Diferença } \\
\text { entre os retornos médios dos portfólios } \\
\text { de ações com desempenho } \\
\text { operacional robusto e os com } \\
\text { desempenho operacional fraco. }\end{array}$ & $\begin{array}{l}R M W_{t}=\bar{R}_{R}-\bar{R}_{W} \\
\bar{R}_{R}=\frac{S R_{t}+B R_{t}}{2} ; \bar{R}_{W}=\frac{S W_{t}+B W_{t}}{2}\end{array}$ & 5 fatores \\
\hline $\begin{array}{l}\text { Fator CMA - investimento. Diferença } \\
\text { entre os retornos médios dos portfólios } \\
\text { de empresas que realizaram } \\
\text { investimentos conservadores e os das } \\
\text { empresas que realizaram investimentos } \\
\text { agressivos }\end{array}$ & $\begin{array}{l}C M A_{t}=\bar{R}_{C}-\bar{R}_{A} \\
\bar{R}_{C}=\frac{S C_{t}+B C_{t}}{2} ; \bar{R}_{A}=\frac{S A_{t}+B A_{t}}{2}\end{array}$ & 5 fatores \\
\hline
\end{tabular}

Fonte: Elaborada pelos autores com base em Fama e French $(1993,2015)$ e Carhart (1997). 


\subsection{Variáveis Dependentes - retornos dos portfólios left-hand-side (LHS)}

As variáveis dependentes utilizadas em ambas as etapas desta análise são os excessos de retorno dos portfólios LHS. Para cada ano do período amostral, as ações foram divididas em cinco quintis segundo a classificação por tamanho. Em seguida, cada um desses quintis foi reordenado novamente de acordo com uma segunda variável (segundo ranqueamento) e dividido em quintis. Os portfólios foram formados com as seguintes combinações: (i) tamanho e índice book-to-market; (ii) tamanho e lucratividade; e (iii) tamanho e investimento. Dessa forma, para cada variável considerada na segunda classificação, foram formados 25 portfólios. As variáveis dependentes dos três modelos analisados foram, então, calculadas como os excessos de retorno desses portfólios em relação ao retorno da taxa de juros livre de risco (cuja proxy foi o CDI), ponderados pelo valor de mercado dos ativos que os compõem.

\subsection{Estimação dos modelos}

Os modelos de três (equação 1), quatro (equação 2) e cinco fatores (equação 3) foram estimados conforme a metodologia de Fama e MacBeth (1973), que compreende a realização de regressões em dois passos. No primeiro, os excessos de retorno dos 75 portfólios LHS (variáveis dependentes) formados com base nas anomalias tamanho, índice book-to-market, lucratividade e investimento - mantendo-se constante o tamanho; e variando-se a segunda característica - foram regredidos sobre os fatores RHS (fatores de risco) dos modelos estimados - MKT, SMB, HML, WML, RMW e CMA (variáveis independentes), conforme cada modelo. Ou seja, esse passo envolveu a estimação dos modelos de séries temporais para obtenção das sensibilidades dos retornos dos portfólios LHS às variações nos retornos dos fatores RHS dos modelos de três, quatro e cinco fatores. Como a intenção (primeira hipótese deste estudo) era verificar se o modelo de cinco fatores produziu melhorias na explicação dos retornos médios dos portfólios LHS, nesse primeiro passo, avaliou-se, por meio do teste GRS, o desempenho dos três modelos de precificação analisados. O teste GRS - utilizado por Fama e French $(1993,1996,2015,2017)$ em seus respectivos estudos - é construído de modo a verificar se os interceptos dos modelos de regressão de séries temporais são, em conjunto, estatisticamente iguais à zero (hipótese nula) ou diferentes de zero (hipótese alternativa). Para isso, foram calculados os valores médios das estatísticas descritivas das estimativas das regressões. Segundo Fama e French $(2015,2017)$, as seguintes estatísticas permitem avaliar modelos concorrentes: (i) GRS e seu p-valor; (ii) A|ai| - valores absolutos dos interceptos $\alpha_{i}$ (representa a parte dos retornos dos portfólios LHS que o modelo não explica); (iii) $s(\alpha)$ - desvio-padrão dos valores dos interceptos; (iv) $A\left|a_{i}\right| / A\left|r_{i}\right|$ - valor médio absoluto dos interceptos $\alpha_{i}$ sobre o valor absoluto de $r_{i}$ (diferença entre o valor absoluto do retorno médio do portfólio $i$ e a média dos retornos de todos os portfólios formados a partir das variáveis consideradas na construção do portfólio $I$ ) - mede a dispersão dos interceptos dos modelos em relação à dispersão dos retornos dos portfólios LHS; e (v) $R^{2}$ adj. - coeficientes de determinação ajustados.

No segundo passo, o objetivo foi verificar se existem, no mercado acionário brasileiro, prêmios associados aos coeficientes de risco sistêmico estimados no primeiro passo (sensibilidades associadas aos fatores RHS), segunda hipótese deste artigo. Ao se analisar o impacto desses coeficientes de risco sobre os retornos, verifica-se a precificação do risco que representam. Assim, nessa etapa, foram estimadas as regressões cross-section dos excessos de retorno dos portfólios LHS (variáveis dependentes) sobre os coeficientes de sensibilidade associados aos fatores RHS (variáveis independentes). Em seguida, as estimativas obtidas nessas regressões foram analisadas por meio de estatísticas descritivas. Essa análise é importante porque mostra se existe a precificação dos riscos sistêmicos, isto é, se os investidores exigem um retorno mais alto porque percebem determinado tipo de risco (se o descontam).

\section{Discussão dos Resultados}

\subsection{Estatísticas Descritivas dos Fatores RHS}

As estatísticas descritivas dos fatores RHS (variáveis independentes nas regressões do primeiro passo) dos modelos estimados são apresentadas na tabela 3. Dentre todos os fatores, SMB foi aquele com o maior retorno mensal médio (e estatisticamente significativo): (i) 1,06 nos modelos de três e quatro fatores; e (ii) 1,03 no modelo de cinco fatores. No Brasil, as evidências são diversas para esse fator: Machado e Medeiros (2011) e Siqueira et al. (2017) encontraram valores médios negativos; e Martins e Eid Jr. (2015) e Vieira et al. (2017), positivos. O segundo maior retorno médio (prêmio) foi o de WML, 0,61. Porém, assim como em Santos et al. (2012), essa média não se mostrou estatisticamente significativa.

Verificou-se um prêmio mensal médio de 0,25 para MKT em todos os modelos. Fama e French $(1993,2015)$ documentaram um prêmio associado a MKT de (i) 0,43 no modelo de três fatores e (ii) 0,50 no de cinco fatores. Prêmios relativamente maiores foram registrados em: (i) Santos et al. (2012) - 1,56 no período 1995-2006; e (ii) Martins e Eid Jr. (2015) - 0,86 no período 2000-2012. Possivelmente, essa divergência deva-se às diferenças de amostra e períodos analisados. Quanto aos demais fatores, $\mathrm{HML}$ apresentou um prêmio de 0,27; e CMA, de 0,54. RMW não proporcionou prêmio (retorno médio negativo). 
Nesse caso, é possível depreender que empresas brasileiras com lucratividade elevada parecem não proporcionar retornos superiores aos das de lucratividade baixa, o que sugere a possível irrelevância desse fator. Nenhum desses fatores se mostrou estatisticamente significativo, entretanto.

Assim como em Martins e Eid Jr. (2015), o valor médio de SMB foi o único significativo nesta análise, o que corrobora a existência do efeito tamanho no Brasil. Santos et al. (2012), por sua vez, encontraram significância apenas para HML. Dessa forma, os resultados aqui discutidos encontram semelhanças com os de alguns estudos de precificação no mercado brasileiro. Verificam-se, no entanto, resultados dissonantes: Machado e Medeiros (2011) encontraram significância estatística para as médias dos fatores dos modelos de três e quatro fatores, com exceção de SMB. Siqueira et al. (2017) documentaram que o fator relacionado ao tamanho apresentou a menor média dos retornos para os modelos de três e quatro fatores. Entende-se que essas diferenças se devam, possivelmente, ao número de portfólios e aos períodos analisados, que divergem entre os estudos.

Tabela 3

Estatísticas descritivas dos fatores RHS (modelos de três, quatro e cinco fatores)

Painel (a): Modelos de três e quatro fatores

\begin{tabular}{|c|c|c|c|c|c|}
\hline 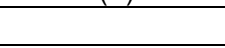 & MKT & SMB & HML & & WML \\
\hline Média & 0,25 & 1,06 & 0,27 & & 0,61 \\
\hline Desvio Padrão & 6,03 & 4,09 & 5,53 & & 5,94 \\
\hline Assimetria & $-0,56$ & 0,30 & $-0,70$ & & $-0,19$ \\
\hline Curtose & 1,83 & 0,28 & 4,52 & & 1,19 \\
\hline Estatística t & 0,62 & 3,81 & 0,72 & & 1,51 \\
\hline P-valor & 0,54 & 0,00 & 0,47 & & 0,13 \\
\hline \multicolumn{6}{|c|}{ Painel (b): Modelo de cinco fatores } \\
\hline & MKT & SMB & HML & RMW & CMA \\
\hline Média & 0,25 & 1,03 & 0,27 & $-0,23$ & 0,54 \\
\hline Desvio Padrão & 6,03 & 3,95 & 5,53 & 4,65 & 5,00 \\
\hline Assimetria & $-0,56$ & 0,24 & $-0,70$ & $-0,83$ & 0,37 \\
\hline Curtose & 1,83 & 0,07 & 4,52 & 3,76 & 2,80 \\
\hline Estatística t & 0,62 & 3,84 & 0,72 & $-0,73$ & 1,58 \\
\hline P-valor & 0,54 & 0,00 & 0,47 & 0,47 & 0,12 \\
\hline
\end{tabular}

Fonte: Dados da pesquisa.

\subsection{Estatísticas Descritivas dos Portfólios LHS}

A tabela 4 apresenta os excessos de retorno médios dos portfólios LHS (variável dependente) e os desvios padrão de cada um deles. No painel (a), apresentam-se essas estatísticas para os 25 portfólios formados segundo tamanho e índice book-to-market. Nas colunas, observa-se o efeito tamanho: um decréscimo do retorno médio de cada portfólio à medida que o tamanho das empresas aumenta (salvo algumas exceções). Esse efeito se assemelha ao documentado por Fama e French (2015). Não obstante, contrariando-o, Mussa et al. (2009) e Siqueira et al. (2017) encontraram retornos maiores para portfólios de ações de empresas grandes negociadas no mercado brasileiro. Nas linhas do painel (a), ao comparar os retornos dos portfólios low e high, não é possível observar claramente o efeito do índice book-to-market. Como apontado por Fama e French (2015), o efeito valor foi observado mais claramente para ações de empresas pequenas: (i) na linha small, o retorno médio passa de 0,46 a 1,00; em contraste, (ii) na linha big, não se verifica um padrão de crescimento.

No painel (b), as estatísticas descritivas referem-se aos portfólios formados segundo tamanho e investimento. Fama e French (2015) verificaram que, à medida que se passa das ações com investimentos baixos (conservadores) para aquelas com investimentos altos (agressivos), o retorno médio tende a diminuir. Porém, esse efeito não foi documentado neste estudo.

Por fim, no painel (c), são exibidas as estatísticas descritivas para os portfólios formados por tamanho e lucratividade. Elas corroboram o efeito lucratividade documentado por Novy-Marx (2013) e Fama e French (2015): para cada quintil segundo o tamanho, os portfólios de ações de empresas com lucratividade alta são associados com retornos médios maiores, quando comparados aos de ações de empresas com lucratividade baixa. Porém, esse resultado difere do de Siqueira et al. (2017) e Martins e Eid Jr. (2015), que não encontraram padrões nos retornos médios para os portfólios segundo tamanho e lucratividade.

\subsection{Primeiro Passo: Estatísticas de Teste das Regressões (modelos de séries temporais)}

$\mathrm{Na}$ tabela 5, apresentam-se os resultados dos testes realizados para as regressões do primeiro passo (modelos de séries temporais) relativas aos modelos de três, quatro e cinco fatores - conduzidas separadamente para os portfólios formados segundo o tamanho e as características índice book-to-market (painel (a)), investimento (painel (b)) e lucratividade (painel (c)). Como em Fama e French $(2015,2017)$, 
para avaliar o desempenho dos modelos fatoriais foram calculadas as estatísticas-sumário dos parâmetros das regressões estimadas no primeiro passo, a saber: (i) média da estatística de teste GRS e seu p-valor; (ii) média dos valores absolutos dos interceptos (A|ai|); (iii) média dos desvios padrão dos interceptos (s(a)); (iv) média dos interceptos absolutos em relação aos desvios dos retornos dos portfólios LHS (A|ai $\left.|/ A| \mathrm{r}_{\mathrm{i}} \mid\right)$; e (v) média dos coeficientes de determinação ajustados ( $R^{2}$ adj.).

Tabela 4

Estatísticas descritivas dos portfólios LHS

Painel (a): tamanho - índice book-to-market

\begin{tabular}{|c|c|c|c|c|c|c|c|c|c|c|}
\hline & \multicolumn{5}{|c|}{ Média } & \multicolumn{5}{|c|}{ Desvio padrão } \\
\hline & Low & 2 & 3 & 4 & High & Low & 2 & 3 & 4 & High \\
\hline Small & 0,45 & 0,53 & 1,45 & 1,58 & 1,00 & 10,45 & 8,91 & 9,28 & 11,20 & 8,61 \\
\hline 2 & 0,67 & 1,21 & 0,71 & 0,54 & 0,96 & 9,58 & 8,19 & 7,70 & 7,60 & 8,43 \\
\hline 3 & 0,09 & 0,67 & 0,68 & 1,16 & 0,86 & 14,66 & 7,63 & 7,99 & 7,17 & 8,14 \\
\hline 4 & 0,58 & 0,32 & 0,55 & 0,49 & 0,69 & 7,26 & 7,09 & 6,77 & 7,04 & 7,26 \\
\hline Big & $-0,17$ & $-0,09$ & 0,08 & 0,05 & $-0,05$ & 7,18 & 6,52 & 7,49 & 6,96 & 8,93 \\
\hline
\end{tabular}

Painel (b): tamanho - investimento

\begin{tabular}{|c|c|c|c|c|c|c|c|c|c|c|}
\hline & \multicolumn{5}{|c|}{ Média } & \multicolumn{5}{|c|}{ Desvio padrão } \\
\hline & Low & 2 & 3 & 4 & High & Low & 2 & 3 & 4 & High \\
\hline Small & 0,46 & 1,00 & 0,35 & 1,58 & 1,50 & 10,91 & 11,49 & 9,76 & 8,62 & 8,56 \\
\hline 2 & 0,74 & 0,59 & 1,11 & 0,55 & 1,17 & 9,39 & 7,60 & 8,04 & 6,93 & 8,95 \\
\hline 3 & 1,05 & 1,29 & 0,81 & $-0,87$ & 0,43 & 6,76 & 7,40 & 10,10 & 16,09 & 8,36 \\
\hline 4 & 0,71 & 0,41 & 0,45 & 0,56 & 0,28 & 6,67 & 6,61 & 7,12 & 7,60 & 7,67 \\
\hline Big & $-0,13$ & $-0,02$ & 0,06 & 0,08 & $-0,33$ & 6,45 & 8,08 & 8,47 & 7,21 & 8,04 \\
\hline \multicolumn{11}{|c|}{ Painel (c): tamanho - lucratividade } \\
\hline & \multicolumn{5}{|c|}{ Média } & \multicolumn{5}{|c|}{ Desvio padrão } \\
\hline & Low & 2 & 3 & 4 & High & Low & 2 & 3 & 4 & High \\
\hline Small & 0,63 & 0,58 & 0,56 & 1,39 & 1,68 & 13,00 & 9,76 & 7,48 & 8,81 & 11,34 \\
\hline 2 & 0,87 & 0,91 & 0,20 & 0,59 & 1,52 & 10,24 & 8,37 & 7,80 & 6,62 & 7,72 \\
\hline 3 & 0,72 & 0,00 & 1,07 & 1,38 & $-0,02$ & 9,31 & 6,98 & 8,65 & 10,42 & 13,97 \\
\hline 4 & 0,24 & 0,24 & $-0,34$ & 0,93 & 1,18 & 8,15 & 7,36 & 6,32 & 6,29 & 7,25 \\
\hline Big & $-0,36$ & $-0,43$ & $-0,31$ & 0,25 & 0,10 & 8,51 & 7,83 & 7,91 & 7,31 & 6,60 \\
\hline
\end{tabular}

Fonte: Dados da pesquisa.

As estatísticas de teste médias sugerem: nos painéis (a) e (c), melhor desempenho do modelo de cinco fatores (menor estatística GRS e maior p-valor), o que corrobora os resultados de Fama e French (2015), Martins e Eid Jr. (2015) e Siqueira et al. (2017); e, no painel (b), do modelo de quatro fatores. Além disso, verifica-se que a hipótese nula do teste GRS foi rejeitada para os modelos de três e quatro fatores estimados para os portfólios segundo tamanho e lucratividade. Nesse caso, os resultados indicam que os fatores não foram suficientes para explicar os retornos dos portfólios LHS e que outros poderiam ser a eles adicionados.

Os valores da estatística A|ai| também indicam melhor performance do modelo de cinco fatores para portfólios formados por tamanho e índice book-to-market; e para portfólios por tamanho e lucratividade. Para os portfólios formados por tamanho e investimento, o modelo de quatro fatores apresentou o melhor desempenho.

Os valores médios de $\mathrm{R}^{2}$ adj. dos modelos estimados indicam melhor ajuste do modelo de cinco fatores (seguido pelos modelos de quatro e três fatores). Quando comparados com os resultados de Fama e French (2015), os coeficientes de determinação aqui registrados são bastante inferiores.

Tabela 5

Estimativas médias das regressões do primeiro passo para os modelos fatoriais Painel (a): Portfólios segundo tamanho - índice book-to-market

\begin{tabular}{|c|c|c|c|c|c|c|}
\hline & GRS & p-valor & $\mathbf{A}|\mathbf{\alpha} \mathbf{i}|$ & $s(\alpha)$ & A|ai|/A|ri| & $\mathbf{R}^{2}$ adj. \\
\hline 3 fatores & 1,0545 & 0,3998 & 0,2593 & 0,2872 & 0,7312 & 0,525361 \\
\hline 4 fatores & 1,2042 & 0,2400 & 0,2722 & 0,3162 & 0,7676 & 0,533313 \\
\hline 5 fatores & 0,8737 & 0,6414 & 0,2498 & 0,3060 & 0,7044 & 0,541159 \\
\hline
\end{tabular}

Painel (b): Portfólios segundo tamanho - investimento

\begin{tabular}{|c|c|c|c|c|c|c|}
\hline & GRS & p-valor & $\mathbf{A}|\mathbf{\alpha i}|$ & $s(\alpha)$ & $\mathbf{A}|\mathbf{\alpha i}| / \mathbf{A}|\mathbf{r i}|$ & $\mathbf{R}^{2}$ adj. \\
\hline 3 fatores & 1,1657 & 0,2761 & 0,3631 & 0,4413 & 0,8293 & 0,480316 \\
\hline 4 fatores & 0,9819 & 0,4934 & 0,3622 & 0,4182 & 0,8272 & 0,487639 \\
\hline 5 fatores & 1,0996 & 0,3466 & 0,3705 & 0,5070 & 0,8461 & 0,509247 \\
\hline \multicolumn{7}{|c|}{ Painel (c): Portfólios segundo tamanho - lucratividade } \\
\hline & GRS & p-valor & $\mathbf{A}|\mathbf{\alpha} \mathbf{i}|$ & $s(\alpha)$ & $\mathbf{A}|\mathbf{\alpha i}| / \mathbf{A}|\mathbf{r i}|$ & $\mathbf{R}^{2} \mathbf{a d j}$ \\
\hline 3 fatores & 1,8679 & 0,0103 & 0,4380 & 0,4720 & 0,8543 & 0,482783 \\
\hline 4 fatores & 1,7613 & 0,0184 & 0,4180 & 0,4516 & 0,8153 & 0,492782 \\
\hline 5 fatores & 1,3852 & 0,1151 & 0,3070 & 0,3599 & 0,5989 & 0,512195 \\
\hline
\end{tabular}

Fonte: Dados da pesquisa. 
Em suma, as evidências aqui relatadas sugerem que os retornos dos portfólios de ações negociadas no mercado de capitais brasileiro são mais bem explicados pelos modelos de cinco e de quatro fatores, quando comparados ao modelo de três fatores. De forma a analisar mais profundamente essa hipótese, realizaram-se as regressões do primeiro passo com diferentes combinações de fatores, sendo os seus resultados apresentados e discutidos na próxima seção.

\subsection{Regressões com Diferentes Combinações de Fatores RHS}

Com o propósito de verificar qual conjunto de fatores compõe o melhor modelo para a amostra aqui analisada, apresentam-se, na tabela 6, os resultados do teste GRS e as estatísticas descritivas para diversas combinações de fatores. Buscou-se também realizar os testes sem o fator HML de modo a verificar, para o mercado brasileiro, a sua relevância na precificação - isso porque esse fator se mostrou redundante em estudos como os de Fama e French (2015), Siqueira et al. (2017) e Leite et al. (2018). No painel (a) - portfólios formados por tamanho e índice book-to-market-, o melhor desempenho foi observado para a combinação dos fatores: $R_{m}-R_{f}$ e SMB (menor valor da estatística GRS e maior $p$-valor). No painel (b) - portfólios formados por tamanho e investimento -, a combinação dos fatores $R_{m}-R_{f}$, SMB e WML produziu o modelo com a melhor performance. No entanto, os resultados de ambos os grupos podem ser considerados inferiores, se comparados àqueles dos mesmos conjuntos de portfólios apresentados anteriormente na tabela 5. No painel (c) - portfólios formados por tamanho e lucratividade -, a hipótese nula do teste GRS é rejeitada para todas as combinações de fatores, indicando a insuficiência dos modelos para explicar os retornos médios dos portfólios LHS.

Tabela 6

Estimativas médias das regressões do primeiro passo para diferentes combinações de fatores RHS

Painel (a): Portfólios segundo tamanho - índice book-to-market

\begin{tabular}{|c|c|c|c|c|c|c|}
\hline Fatores & GRS & p-valor & $\mathbf{A}|\boldsymbol{\alpha i}|$ & $s(\alpha)$ & $\mathbf{A}|\mathbf{\alpha i}| / \mathbf{A}|\mathbf{r i}|$ & R2 adj. \\
\hline $\mathrm{Rm}-\mathrm{Rf} / \mathrm{SMB}$ & 1,0623 & 0,3902 & 0,2811 & 0,3282 & 0,7926 & 0,4873 \\
\hline Rm-Rf / SMB / WML & 1,2092 & 0,2355 & 0,3049 & 0,3678 & 0,8595 & 0,4978 \\
\hline Rm-Rf / SMB / RMW & 1,1464 & 0,2957 & 0,3601 & 0,4862 & 1,0152 & 0,5121 \\
\hline $\mathrm{Rm}-\mathrm{Rf} / \mathrm{SMB} / \mathrm{CMA}$ & 1,1312 & 0,3116 & 0,3046 & 0,3850 & 0,8589 & 0,5136 \\
\hline Rm-Rf / SMB / CMA / RMW & 1,1342 & 0,3085 & 0,3448 & 0,4636 & 0,9720 & 0,5227 \\
\hline \multicolumn{7}{|c|}{ Painel (b): Portfólios segundo tamanho - investimento } \\
\hline Fatores & GRS & p-valor & $\mathbf{A}|\mathbf{\alpha} \mathbf{i}|$ & $s(\alpha)$ & $\mathbf{A}|\mathbf{\alpha i}| / \mathbf{A}|\mathbf{r i}|$ & R2 adj. \\
\hline $\mathrm{Rm}-\mathrm{Rf} / \mathrm{SMB}$ & 1,1857 & 0,2568 & 0,3738 & 0,4678 & 0,8537 & 0,4655 \\
\hline Rm-Rf / SMB / WML & 1,0377 & 0,4208 & 0,3945 & 0,4675 & 0,9008 & 0,4739 \\
\hline $\mathrm{Rm}-\mathrm{Rf} / \mathrm{SMB} / \mathrm{RMW}$ & 1,2653 & 0,1896 & 0,4092 & 0,5791 & 0,9345 & 0,4837 \\
\hline $\mathrm{Rm}-\mathrm{Rf} / \mathrm{SMB} / \mathrm{CMA}$ & 1,2920 & 0,1704 & 0,4020 & 0,5056 & 0,9179 & 0,4958 \\
\hline $\mathrm{Rm}-\mathrm{Rf} / \mathrm{SMB} / \mathrm{CMA} / \mathrm{RMW}$ & 1,2619 & 0,1923 & 0,4064 & 0,5726 & 0,9279 & 0,5040 \\
\hline \multicolumn{7}{|c|}{ Painel (c): Portfólios segundo tamanho - lucratividade } \\
\hline Fatores & GRS & p-valor & $\mathbf{A}|\boldsymbol{\alpha i}|$ & $s(\alpha)$ & $\mathbf{A}|\mathbf{\alpha i}| / \mathbf{A}|\mathbf{r i}|$ & R2 adj. \\
\hline $\mathrm{Rm}-\mathrm{Rf} / \mathrm{SMB}$ & 1,8596 & 0,0108 & 0,4323 & 0,4590 & 0,8433 & 0,4668 \\
\hline Rm-Rf / SMB / WML & 1,7756 & 0,0170 & 0,3806 & 0,4310 & 0,7423 & 0,4780 \\
\hline $\mathrm{Rm}-\mathrm{Rf} / \mathrm{SMB} / \mathrm{RMW}$ & 1,6102 & 0,0400 & 0,3442 & 0,4063 & 0,6713 & 0,5006 \\
\hline $\mathrm{Rm}-\mathrm{Rf} / \mathrm{SMB} / \mathrm{CMA}$ & 1,8268 & 0,0129 & 0,4326 & 0,4539 & 0,8437 & 0,4852 \\
\hline Rm-Rf / SMB / CMA / RMW & 1,5957 & 0,0430 & 0,3430 & 0,3980 & 0,6691 & 0,5061 \\
\hline
\end{tabular}

Fonte: Dados da pesquisa.

De forma geral, os resultados discutidos nesta seção apontam que as diferentes combinações de fatores não foram capazes de apresentar um desempenho superior aos dos modelos estimados em sua estrutura original (estimativas apresentadas na tabela 5).

\subsection{Segundo Passo: Resultados das Regressões Cross-section}

Nas regressões cross-section estimadas no segundo passo da metodologia de Fama e MacBeth (1973), a variável dependente dos modelos foi o excesso de retorno médio de cada um dos 75 portfólios LHS, e as variáveis independentes foram os coeficientes de inclinação estimados nas regressões do primeiro passo (sensibilidades associadas aos fatores RHS).

$\mathrm{Na}$ tabela 7, apresentam-se os valores médios das estimativas dos parâmetros das regressões cross-section, bem como as estatísticas dos testes das hipóteses subjacentes aos modelos de regressão. 0 modelo de cinco fatores apresentou o maior coeficiente de determinação ajustado, cerca de $66 \%$. Os valores dessas estatísticas para os demais modelos foram similares: (i) modelo de três fatores, $60 \%$ (aproximadamente); e (ii) modelo de quatro fatores, 61\%. Os resultados de Mussa et al. (2009) corroboram com os aqui relatados: $\mathrm{R}^{2}$ adj. maior para o modelo de quatro fatores, em relação ao do modelo de três fatores. Rizzi (2012), ao contrário, encontrou $\mathrm{R}^{2}$ adj. maior para o modelo de três fatores em relação ao do modelo de quatro fatores. 
Todos os coeficientes de inclinação do modelo de três fatores - b, s e $\mathrm{h}$ - revelaram-se estatisticamente significativos, sugerindo a precificação dos riscos de mercado, tamanho e índice book-tomarket pelos investidores do mercado. Para o modelo de quatro fatores, o coeficiente atrelado ao momento - w - foi o único não-significativo, o que sugere a inexistência de um prêmio de risco associado a ele. Esses resultados corroboram, em parte, os de Mussa et al (2009), que registraram apenas os prêmios de mercado e índice book-to-market. Para o modelo de cinco fatores, os coeficientes relativos à lucratividade e ao investimento $-r$ e c - não se mostraram significativos, indicando a inexistência de prêmios de risco associados aos fatores de lucratividade e investimento. Em geral, os fatores mercado, tamanho e índice book-to-market são aqueles que mais parecem explicar as variações dos retornos cross-section dos portfólios. A adição dos fatores momento, lucratividade e investimento aos modelos de precificação de ativos não parece ser pertinente para a amostra analisada. Os resultados de Mussa et al. (2009) e Rizzi (2012), que testaram os modelos de três e quatro fatores para o mercado brasileiro, utilizando a metodologia de dois passos, foram diferentes dos aqui relatados: para ambos os modelos por eles testados, o fator de mercado e o índice book-to-market mostraram-se significativos; e os fatores tamanho e momento não se revelaram significantes.

Além disso, pode-se visualizar na tabela 7 que as estimativas médias dos interceptos dos modelos estimados se mostraram significativas, sugerindo que os riscos analisados (variáveis independentes dos três modelos testados no segundo passo) não foram suficientes para explicar o excesso de retorno crosssection dos portfólios LHS. Possivelmente, outros eventos, por exemplo, os de natureza macroeconômica, como crises financeiras, ou os relativos ao desempenho (características específicas) das empresas frente aos ciclos de negócios poderiam contribuir para explicar os retornos. Ou seja, outros fatores não incluídos nos modelos poderiam ajudar a explicar os retornos dos portfólios de ações negociadas no mercado brasileiro.

\section{Tabela 7}

Estimativas médias das regressões do segundo passo (cross-section)

Painel (a): Modelo de três fatores

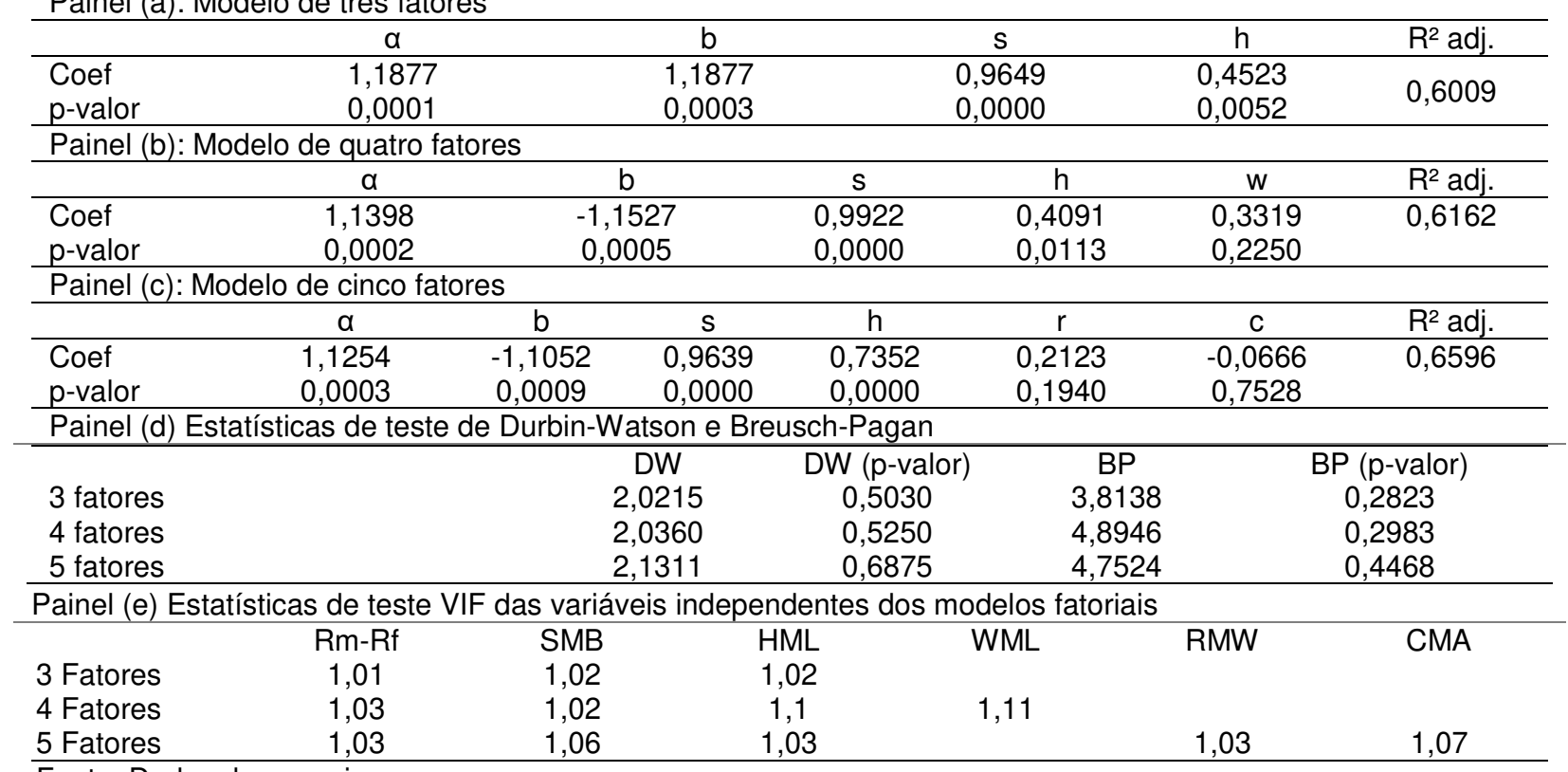

Fonte: Dados da pesquisa.

Nota: os coeficientes b, s, h, w, r e c são, respectivamente, dos fatores $R_{m}-R_{f}, S M B, H M L, W M L, R M W$ e $C M A$; $\alpha$ é o intercepto. No painel (d), as estatísticas de teste Durbin-Watson indicam que não há problemas de autocorrelação. As estatísticas do teste de Breusch-Pagan revelam que não há heteroscedasticidade. No painel (e), as estatísticas de teste VIF sugerem ausência de multicolinearidade entre as variáveis explicativas.

\section{Conclusão}

Este estudo teve dois propósitos. O primeiro consistiu em analisar se o modelo de cinco fatores de Fama e French (2015) tem melhor performance na explicação dos retornos de portfólios de ações negociadas no mercado de capitais brasileiro, quando comparada aos de outros modelos anteriores - três fatores de Fama e French (1993) e quatro fatores de Carhart (2007). O segundo, em verificar se os riscos sistêmicos associados aos fatores desses modelos são precificados pelos investidores. Para realizar a análise, seguiram-se os procedimentos desses autores, sendo os portfólios construídos com base nas anomalias tamanho, índice book-to-market, momento, lucratividade e investimento.

Inicialmente, procurou-se analisar as estatísticas descritivas dos fatores RHS, empregados posteriormente como variáveis independentes dos modelos estimados no primeiro passo da metodologia de 
Fama e MacBeth. Nessa análise, os resultados mostraram que o fator SMB foi o único em que o valor médio se mostrou significativo estatisticamente em todos os modelos analisados. Em seguida, as estatísticas descritivas dos portfólios LHS, os retornos médios e os desvios padrão dos portfólios utilizados como variáveis dependentes, sugeriram os efeitos: (i) tamanho - para os portfólios formados por tamanho e índice book-to-market; (ii) valor (relativo ao índice book-to-market) - que se mostrou mais pronunciado para ações de empresas pequenas; e (iii) lucratividade. Esses resultados iniciais já sugeriam que o investimento não seria precificado pelo mercado.

Na sequência, a análise dos resultados foi desenvolvida em dois passos. No primeiro, os modelos de séries temporais foram estimados para obter os impactos das variações nos fatores RHS (fatores de risco) sobre as variações nos retornos dos portfólios LHS, bem como os coeficientes de intercepto. Avaliouse, então, o desempenho dos três modelos fatoriais a partir das estatísticas referentes aos interceptos. No segundo, os coeficientes dos fatores RHS estimados no passo anterior foram utilizados para testar a hipótese de existência de prêmios de risco associados aos fatores.

Nas regressões do primeiro passo dos modelos de três, quatro e cinco fatores, verificou-se que o modelo de cinco fatores tem o melhor desempenho na explicação dos retornos médios dos portfólios, o que corrobora os resultados de Fama e French (2015) e, dessa forma, contribui como um teste out-of-sample do modelo de cinco fatores, visto que ele se mostrou superior aos demais para a amostra do mercado brasileiro aqui analisada. Essas evidências corroboram a primeira hipótese deste estudo, bem como os resultados documentados por Siqueira et al. (2017) e Leite et al. (2018). Ao realizar a análise entre os diferentes grupos de portfólios LHS, observou-se que os modelos estimados a partir dos fatores construídos segundo tamanho e investimento apresentam melhor desempenho, sugerindo que a escolha da anomalia para classificar os retornos dos portfólios é relevante. No total, encontrou-se suporte para a primeira hipótese deste estudo: o modelo de cinco fatores tem uma performance superior em comparação às dos modelos de três e quatro fatores.

Nas regressões do segundo passo, os resultados permitiram verificar se os coeficientes obtidos nos modelos estimados no primeiro passo ajudam a explicar o retorno dos portfólios LHS. Embora o modelo de cinco fatores tenha apresentado o maior coeficiente de determinação ajustado em comparação aos demais, os resultados evidenciaram que nenhum dos modelos aqui testados foi capaz de explicar totalmente os retornos cross-section dos portfólios LHS, já que restou uma proporção da variância desses retornos que não foi explicada pelos fatores neles incluídos (os interceptos se mostraram significativos em todos os modelos). O tamanho foi o fator de risco mais importante no desempenho dos modelos, sendo significativo em todos os modelos estimados. Os fatores momento, investimento e lucratividade não se mostraram significativos estatisticamente. Nas regressões cross-section, por meio das quais se testou a precificação dos riscos associados ao mercado, tamanho, índice book-to-market, momento, lucratividade e investimento, o modelo mais adequado foi o de três fatores, haja vista a significância estatística de todos os seus fatores de risco, o que não se observou para os demais modelos testados. Com isso, não se pode corroborar a segunda hipótese desta pesquisa, uma vez que os fatores de risco do modelo de cinco fatores não são precificados pelos investidores.

Conclui-se, assim, que no mercado brasileiro o modelo de cinco fatores apresenta um desempenho superior aos dos modelos de três e quatro fatores. No entanto, os riscos associados à lucratividade e ao investimento não são precificados. Os resultados mostraram que os investidores exigem prêmios de risco associados ao tamanho, ao índice book-to-market e à carteira de mercado. Esse resultado pode decorrer do fato de que as ações na amostra sejam, em grande parte, de empresas pequenas, que são menos lucrativas e realizam menos investimentos e, por isso, não há prêmios associados a esses riscos.

Por fim, outra explicação para a inexistência dos prêmios de risco do modelo de cinco fatores talvez seja o fato de que os retornos dos portfólios sejam gerados por outros eventos, por exemplo, os de natureza macroeconômica, como crises financeiras, ou aqueles específicos das empresas ao longo dos ciclos de negócios, ou, ainda, por aspectos que influenciam diferentemente os setores de atividades das empresas com ações negociadas no mercado de capitais, os quais poderiam contribuir para explicá-los, mas não foram considerados, o que representaria uma limitação deste estudo.

\section{Referências}

Anbima - Associação Brasileira das Entidades dos Mercados Financeiro e de Capitais. (2020). Emissões ultrapassam $R \$ 300$ bilhões em 2020. Recuperado em 20 de dezembro, 2020, de https://www.anbima.com.br/pt br/informar/relatorios/mercado-de-capitais/boletim-de-mercado-decapitais/emissoes-ultrapassam-r-300-bilhoes-em-2020.htm\#

Atilgan, Y., Demirtas, K. O., \& Gunaydin, A. D. (2020). Predicting equity returns in emerging markets. Emerging Markets Finance and Trade. 56, 1-18. https://doi.org/10.1080/1540496X.2020.1822808

Banz, R. (1981). The relationship between return and market value of common stocks. Journal of Financial Economics, 9(1), 3-18. https://doi.org/10.1016/0304-405X(81)90018-0 
Black, F., Jensen, M. C., \& Scholes, M. (1972). The capital asset pricing model: some empirical Tests. In: Jensen, M. C. (eds) Studies in the Theory of Capital Markets (pp. 79-124). Praeger. Available at SSRN: https://ssrn.com/abstract $=908569$

Carhart, M. M. (1997). On persistence in mutual fund performance. Journal of Finance, 52(1), 57- 82. https://doi.org/10.1111/j.1540-6261.1997.tb03808.x

Fama, E. F., \& French, K. R. (1992). The cross-section of expected stock returns. Journal of Finance, 2(47), 427-466. https://doi.org/10.1111/i.1540-6261.1992.tb04398.x

Fama, E. F., \& French, K. R. (1993). Common risk factors in the returns on stocks and bonds. Journal of Financial Economics, 33(1), 3-56. https://doi.org/10.1016/0304-405X(93)90023-5

Fama, E. F., \& French, K. R. (1996). Multifactor explanation of asset pricing anomalies. Journal of Finance, 56(1), 55-84. https://doi.org/10.1111//.1540-6261.1996.tb05202.x

Fama, E. F., \& French, K. R. (1998). Value versus growth: the international evidence. Journal of Finance, 53(6), 1975-1999. https://www.jstor.org/stable/117458

Fama, E. F., \& French, K. R. (2008). Dissecting anomalies. Journal of Finance, 63(4), 1653-1678. https://doi.org/10.1111/j.1540-6261.2008.01371.x

Fama, E. F., \& French, K. R. (2012). Size, value, and momentum in international stock returns. Journal of Financial Economics, 105(3), 457-472. https://doi.org/10.1016/j.jfineco.2012.05.011

Fama, E. F., \& French, K. R. (2015). A five-factor asset pricing model. Journal of Financial Economics, 116(1), 1-22. https://doi.org/10.1016/j.jfineco.2014.10.010

Fama, E. F., \& French, K. R. (2017). International tests of a five-factor asset pricing model. Journal of Financial Economics, 123(3), 441-463. https://doi.org/10.1016/i.fineco.2016.11.004

Fama, E. F. \& French, K. R. (2018). Choosing Factors. Journal of Financial Economics, 128(2), 234-252. https://doi.org/10.1016/j.jfineco.2018.02.012

Fama, E. F., \& MacBeth, J. D. (1973). Risk, return and equilibrium: empirical test. Journal of Political Economy, 81(3), 607-636. https://doi.org/10.1086/260061

Gregory, A., Tharyan, R. \& Christidis, A. (2013). Constructing and testing alternative versions of the FamaFrench and Carhart models in the UK. Journal of Business Finance \& Accounting, 4O(1) \& (2), 172-214. https://doi.org/10.1111/ibfa.12006

Gibbons, M. R., Ross, S. A., \& Shanken, J. (1989). A test of the efficiency of a given portfolio. Econometrica, 57(5), 1121-1252. https://doi.org/10.2307/1913625

Griffin, J.M. (2002), Are the Fama and French Factors Global or Country Specific? Review of Financial Studies, 15(3), 783-803. https://www.jstor.org/stable/2696721

Jegadeesh, N., \& Titman, S. (1993). Returns to buying winners and selling losers: implications for stock market efficiency. Journal of Finance, 48(1), 65-91. https://doi.org/10.1111/i.1540-6261.1993.tb04702.x

Lakonishok, J., \& Shapiro A. C. (1986). Systematic risk, total risk and size as determinants of stock market returns. Journal of Banking and Finance, 10(1), 115-132. https://doi.org/10.1016/0378-4266(86)90023-3

Leite, A. L., Klotzle, M. C., Pinto, A. C. F., \& Silva, A. F. (2018). Size, value, profitability, and investment: evidence from emerging markets. Emerging Markets Review, 36, 45-59.

https://doi.org/10.1016/j.ememar.2018.04.006

Lintner, J. (1965). The valuation of risk assets and the selection of risky investments in stock portfólios and capital budgets. Review of Economics and Statistics, 47(1), 13-37. http://dx.doi.org/10.2307/1924119 
Machado, M. A. V., \& Medeiros, O. R. (2011). $\square$ odelos de precificação de ativos e o efeito liquidez: evidências empíricas no mercado acionário brasileiro. Revista Brasileira de Finanças, 9(3), 383-412. https://doi.org/10.12660/rbfin.v9n3.2011.2862

Málaga, F. K., \& Securato, J. R. (2004). Aplicação do modelo de três fatores de Fama e French no mercado acionário brasileiro - um estudo empírico do período 1995-2003. Anais do ENANPAD, Curitiba, PR, Brasil, 28.

Markowitz, H. (1952). Portfolio selection. Journal of Finance, 7(1), 77-91. http://dx.doi.org/10.1111/i.1540$\underline{6261.1952 . t b 01525 . x}$

Martins, C. C., \& Eid Jr., W. (2015). Pricing assets with Fama and French 5-Factor Model: a Brazilian market novelty. Anais do SBFIN, São Paulo, SP, Brasil, 15.

Matos, P. R. F., \& Rocha, J. A. T. (2009). Ações e fundos de investimento em ações: fatores de risco comuns. Brazilian Business Review, 6(1), 22-43 http://dx.doi.org/10.15728/bbr.2009.6.1.2

Merton, R. (1973). An intertemporal capital asset pricing model. Econometrica, 41(5), 867-887. https://doi.org/10.2307/1913811

Mossin, J. (1966). Equilibrium in a capital asset market. Econometrica, 34(4), 768-783. https://doi.org/10.2307/1910098

Mussa, A., Rogers, P., \& Securato, J. R. (2009). Modelos de retornos esperados no mercado brasileiro: testes empíricos utilizando metodologia preditiva. Revista de Ciências da Administração, 11(23), 192-216. https://doi.org/10.5007/2175-8077.2009v11n23p192

Novy-Marx, R. (2013). The other side of value: The gross profitability premium. Journal of Financial Economics, 108(1), 1-28. https://doi.org/10.1016/j.jfineco.2013.01.003

Paliienko, O., Naumenkova, S., \& Mishchenko, S. (2020). An empirical investigation of the Fama-French five-factor model. Investment Management and Financial Innovations, 17(1), 143-155.

http://dx.doi.org/10.21511/imfi.17(1).2020.13

Rizzi, L. J. (2012). Análise comparativa de modelos para determinação do custo de capital próprio: CAPM, três fatores de Fama e French (1993) e quatro fatores de Carhart (1997). Dissertação de Mestrado, Universidade de São Paulo, São Paulo, Brasil. Recuperado de https://teses.usp.br/teses/disponiveis/12/12139/tde-18102012-175213/publico/LucianaJulioRizziVC.pdf

Rodrigues, M. R. A. (2000). O efeito valor, o efeito tamanho e o modelo multifatorial: evidências do caso brasileiro. Anais do ENANPAD, Florianópolis, Santa Catarina, Brasil, 24.

Ross, S. (1976). The arbitrage theory of capital asset pricing. Journal of Economic Theory, 13(3), 341-360. https://doi.org/10.1016/0022-0531(76)90046-6

Santos, J. O., Famá, R., \& Mussa, A. (2012). A adição do fator de risco momento ao modelo de precificação de ativos dos três fatores de Fama \& French aplicado ao mercado acionário brasileiro. Revista de Gestão, 19(3), 453-471. https://doi.org/10.5700/rege473

Sharpe, W. F. (1964). Capital asset prices: a theory of market equilibrium under conditions of risk. Journal of Financial Economics, 19(3), 425-442. https://doi.org/10.1111/j.1540-6261.1964.tb02865.x

Siqueira, L. S., Amaral, H. F., \& Correia, L. F. (2017). O efeito do risco de informação assimétrica sobre o retorno de ações negociadas na BM\&FBOVESPA. Revista Contabilidade \& Finanças, 28(75), 425-444. https://doi.org/10.1590/1808-057x201705230

Titman, S. K. C., Wei, J., \& Xie, F. (2004). Capital investments and stock returns. Journal of Financial and Quantitative Analysis, 39(4), 677-700. http://www.jstor.org/stable/30031881

Vieira, M. D. V. V, Maia, V. M., Klotzle, M. C., \& Figueiredo. A. C. (2017). Modelo de cinco fatores de risco: precificando carteiras setoriais no mercado acionário brasileiro. Revista Catarinense da Ciência Contábil, 16(48), 86-104. http://dx.doi.org/10.16930/2237-7662/rccc.v16n48.2376. 
Apêndice 1 - Portfólios RHS formados para os modelos de três, quatro e cinco fatores

Modelo de três fatores de Fama e French (1993)

\begin{tabular}{|c|c|c|c|}
\hline Portfólio & Composição & Portfólio & Composição \\
\hline Small e Low & $\begin{array}{l}\text { Ações com baixo valor de } \\
\text { mercado e baixo book-to- } \\
\text { market }\end{array}$ & Big e Low & 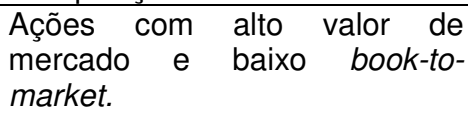 \\
\hline Small e Medium & $\begin{array}{l}\text { Ações com baixo valor de } \\
\text { mercado e médio book-to- } \\
\text { market }\end{array}$ & Big e Medium & $\begin{array}{l}\text { Ações com alto valor de } \\
\text { mercado e médio book-to- } \\
\text { market. }\end{array}$ \\
\hline Small e High & $\begin{array}{l}\text { Ações com baixo valor de } \\
\text { mercado e alto book-to-market }\end{array}$ & Big e High & $\begin{array}{l}\text { Ações com alto valor de } \\
\text { mercado e alto book-to-market. }\end{array}$ \\
\hline \multicolumn{4}{|c|}{ Modelo de quatro fatores de Carhart (1997) } \\
\hline Portfólio & Composição & Portfólio & Composição \\
\hline Small e Loser & $\begin{array}{l}\text { Ações com baixo valor de } \\
\text { mercado e menor retorno } \\
\text { passado }\end{array}$ & Big e Loser & $\begin{array}{l}\text { Ações com alto valor de } \\
\text { mercado e menor retorno } \\
\text { passado }\end{array}$ \\
\hline Small e Medium & $\begin{array}{l}\text { Ações com baixo valor de } \\
\text { mercado e médio retorno } \\
\text { passado }\end{array}$ & Big e Medium & $\begin{array}{l}\text { Ações com alto valor de } \\
\text { mercado e médio retorno } \\
\text { passado }\end{array}$ \\
\hline Small e Winner & $\begin{array}{l}\text { Ações com baixo valor de } \\
\text { mercado e maior retorno } \\
\text { passado }\end{array}$ & Big e Winner & $\begin{array}{l}\text { Ações com alto valor de } \\
\text { mercado e maior retorno } \\
\text { passado }\end{array}$ \\
\hline
\end{tabular}

Modelo de cinco fatores de Fama e French (2015)

\begin{tabular}{|c|c|c|c|}
\hline Portfólio & Composição & Portfólio & Composição \\
\hline Small e Low & $\begin{array}{l}\text { Ações com baixo valor de } \\
\text { mercado e baixo book-to- } \\
\text { market. }\end{array}$ & Big e Low & 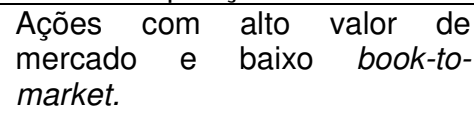 \\
\hline Small e Neutral & $\begin{array}{l}\text { Ações com baixo valor de } \\
\text { mercado e médio book-to- } \\
\text { market. }\end{array}$ & Big e Neutral & $\begin{array}{l}\text { Ações com alto valor de } \\
\text { mercado e médio book-to- } \\
\text { market. }\end{array}$ \\
\hline Small e High & $\begin{array}{l}\text { Ações com baixo valor de } \\
\text { mercado e alto book-to- } \\
\text { market. }\end{array}$ & Big e High & $\begin{array}{l}\text { Ações com alto valor de } \\
\text { mercado e alto book-to-market. }\end{array}$ \\
\hline Small e Weak & $\begin{array}{l}\text { Ações com baixo valor de } \\
\text { mercado e baixa lucratividade. }\end{array}$ & Big e Weak & $\begin{array}{l}\text { Ações com alto valor de } \\
\text { mercado e baixa lucratividade. }\end{array}$ \\
\hline Small e Neutral & $\begin{array}{l}\text { Ações com baixo valor de } \\
\text { mercado } \\
\text { lucratividade. }\end{array}$ & Big e Neutral & $\begin{array}{l}\text { Ações com alto valor de } \\
\text { mercado e média lucratividade. }\end{array}$ \\
\hline Small e Robust & $\begin{array}{l}\text { Ações com baixo valor de } \\
\text { mercado e alta lucratividade. }\end{array}$ & Big e Robust & $\begin{array}{l}\text { Ações com alto valor de } \\
\text { mercado e alta lucratividade }\end{array}$ \\
\hline Small e Conservative & $\begin{array}{l}\text { Ações com baixo valor de } \\
\text { mercado e baixo investimento. }\end{array}$ & Big e Conservative & $\begin{array}{l}\text { Ações com alto valor de } \\
\text { mercado e baixo investimento. }\end{array}$ \\
\hline Small e Neutral & $\begin{array}{l}\text { Ações com baixo valor de } \\
\text { mercado } \\
\text { investimento. }\end{array}$ & Big e Neutral & $\begin{array}{l}\text { Ações com alto valor } \\
\text { mercado e médio investiment }\end{array}$ \\
\hline Small e Aggressive & $\begin{array}{l}\text { Ações com baixo valor de } \\
\text { mercado e alto investimento. }\end{array}$ & Big e Aggressive & $\begin{array}{l}\text { Ações com alto valor de } \\
\text { mercado e alto investimento. }\end{array}$ \\
\hline
\end{tabular}

Fonte: Elaborada pelos autores com base em Fama e French (2015)

\section{NOTAS}

\section{AGRADECIMENTOS}

Agradecemos o apoio do Centro Federal de Educação Tecnológica de Minas Gerias (CEFET-MG), à Coordenação de Aperfeiçoamento de Pessoal de Nível Superior (CAPES), ao Conselho Nacional de Desenvolvimento Científico e Tecnológico (CNPq) e ao Instituto Ânima.

\section{CONTRIBUIÇÃO DE AUTORIA}

Concepção e elaboração do manuscrito: C. F. Maciel, L. F. Correia.

Coleta de dados: C. F. Maciel, J. M. M. Cavalcanti.

Análise de dados: C. F. Maciel, L. F. Correia, H. F. Amaral.

Discussão dos resultados: C. F. Maciel, L. F. Correia, H. F. Amaral, J. M. M. Cavalcanti.

Revisão e aprovação: L. F. Correia, J. M. M. Cavalcanti.

\section{CONJUNTO DE DADOS DE PESQUISA}

O conjunto de dados que dá suporte aos resultados deste estudo não está disponível publicamente.

\section{FINANCIAMENTO}

Em conformidade com a Portaria $n^{\circ} 206$, de 4 de setembro de 2018, "o presente trabalho foi realizado com 
apoio da Coordenação de Aperfeiçoamento de Pessoal de Nível Superior - Brasil (CAPES) - Código de Financiamento 001".

\section{CONSENTIMENTO DE USO DE IMAGEM}

Não se aplica.

\section{APROVAÇÃO DE COMITÊ DE ÉTICA EM PESQUISA}

Não se aplica.

\section{CONFLITO DE INTERESSES}

Não se aplica.

\section{LICENÇA DE USO}

Os Direitos Autorais para artigos publicados neste periódico são do autor, com direitos de primeira publicação para a Revista. Em virtude de aparecerem nesta Revista de acesso público, os artigos são de uso gratuito, com atribuições próprias, em aplicações educacionais, de exercício profissional e para gestão pública. A Revista adotou a licença Creative Commons Atribuição 4.0 Internacional - CC BY NC ND. Esta licença permite acessar, baixar (download), copiar, imprimir, compartilhar, reutilizar e distribuir os artigos desde que com a citação da fonte, atribuindo os devidos créditos de autoria. Nesses casos, nenhuma permissão é necessária por parte dos autores ou dos editores. Autores têm autorização para assumir contratos adicionais separadamente, para distribuição não-exclusiva da versão do trabalho publicada nesta revista (ex.: publicar em repositório institucional ou um capítulo de livro).

\section{PUBLISHER}

Universidade Federal de Santa Catarina. Curso de Ciências Contábeis e Programa de Pós-graduação em Contabilidade. Publicação no Portal de Periódicos UFSC. As ideias expressadas neste artigo são de responsabilidade de seus autores, não representando, necessariamente, a opinião dos editores ou da universidade.

\section{EDITORES}

Carlos Eduardo Facin Lavarda e Suliani Rover

\section{HISTÓRICO}

Recebido em: 29/12/2020 - Revisado por pares em: 19/05/2021 - Reformulado em: 12/07/2021 Recomendado para publicação em: 21/07/2021 - Publicado em: 04/12/2021 